\title{
ASPEK BIOLOGI IKAN LIDAH (Achiroides leuchorhinchos) DAN SEBARAN DI SUNGAI MUSI, SUMATERA SELATAN
}

\author{
Eti Nurhayati1) dan Eko Prianto1) \\ 1) Peneliti pada Balai Riset Perikanan Perairan Umum, Mariana-Palembang \\ Teregristrasi I tanggal: 5 Mei 2008; Diterima setelah perbaikan tanggal: 15 Mei 2008; Disetujui terbit tanggal: 26 Mei 2008
}

\begin{abstract}
ABSTRAK
Penelitian ini dilakukan di Sungai Musi, Sumatera Selatan pada tahun 2007 untuk mempelajari biologi ikan lidah (Achiroides leuchorhinchos) yang meliputi distribusi ukuran, bobot tubuh, kebiasaan makan, fekunditas, serta sebaran di Sungai Musi. Contoh ikan diperoleh dengan alat jaring, jala, dan stroom eksperimen. Hasil penelitian ini menunjukkan bahwa ikan lidah (Achiroides leuchorhinchos) terdapat di Sungai Musi bagian hulu sampai dengan hilir. Ikan ini memiliki pola pertumbuhan allometrik negatif $(b=2.894)$ dengan ikan terbanyak pada kisaran panjang 41 sampai dengan $48 \mathrm{~mm}$ dan 0,5 sampai dengan $1 \mathrm{~g}$. Ikan lidah (Achiroides leuchorhinchos) termasuk ikan karnifora dengan makanan utama kepiting dan makanan pelengkap ikan. Pola pemijahan adalah total spawner dengan fekunditas sekitar $2 \times 10^{3}$ butir telur berukuran rata-rata $0,06 \mathrm{~mm}$. Musim pemijahan ikan lidah (Achiroides leuchorhinchos) diperkirakan terjadi pada bulan Juli (musim kemarau).
\end{abstract}

\section{KATAKUNCl: ～ikan lidah, Achiroides leuchorhinchos, biologi, Sungai Musi \\ ABSTRACT: Biological aspect of tongue fish (Achiroides leuchorhinchos) and its distribution in Musi River of South Sumatera. By: Eti Nurhayati and Eko Prianto}

\begin{abstract}
Research was done in Musi River, South Sumatera in 2007 to study the biology of tongue fish (Achiroides leuchorhinchos) covering distribution of size measure, body wight, food habit, fecundity, and distribution in Musi River. Fish samples were collected by using net and electric fishing. The result shows that tongue fish (Achiroides leuchorhinchos) was found in upstream until downstream. This fish has negative growth allometric pattern $(b=2,894)$. Tongue fish is carnivore with the espesial food $\mathrm{crab}$ and fish as complement food. Its fecunditity pattern is total spawner with number of eggs of about $2 \times 10^{3}$ eggs, size of eggs of $0.06 \mathrm{~mm}$. The spawning season of tongue fish might occur on July (dry season).
\end{abstract}

\section{KEYWORDS: $\quad$ tongue fish, Achiroides leuchorhinchos, biology, Musi River}

\section{PENDAHULUAN}

Sungai Musi yang cukup luas dikenal memiliki keanekaragaman jenis ikan. Salah satunya adalah ikan lidah (Achiroides leuchorhinchos). Ikan lidah (Achiroides leuchorhinchos) ini merupakan ikan demersal yang dicirikan dengan bentuk mulut letaknya agak ke bawah yang digunakan untuk mencari makanan di dasar atau dalam substrat.

Ikan lidah (Achiroides leuchorhinchos) termasuk ke dalam ordo Pleuronectiformes yang merupakan kelompok ikan berbentuk pipih dan memiliki ke-2 mata di 1 permukaan badan. Pleuronectiformes beranggotakan jenis ikan sebelah (famili Bothidae) (famili Bothidae) dan ikan lidah (Achiroides leuchorhinchos, famili Cynoglossidae dan Soleidae). Ikan sebelah (famili Bothidae) memiliki sirip punggung dan sirip dubur yang terpisah dengan sirip ekor, sedangkan pada ikan lidah (Achiroides leuchorhinchos) sirip punggung, sirip dubur, dan sirip ekor bersatu. Kedua mata ikan lidah (Achiroides leuchorhinchos) famili Cynoglossidae terletak di sebelah kiri, sedangkan Soleidae di sebelah kanan. Achiroides leuchorhinchos termasuk ke dalam famili Soleidae.

Menurut www.fishbase.com, ikan lidah (Achiroides leuchorhinchos) jenis Achiroides leuchorhinchos memiliki nilai ekonomis yang sangat tinggi, karena ikan ini berpotensi untuk menjadi salah satu komoditas andalan perikanan pada masa mendatang sehingga populasi ikan ini perlu dikelola dengan baik. Untuk mendukung upaya pengelolaan tersebut, diperlukan informasi tentang aspek biologi dan ekologi ikan tersebut. Beberapa aspek biologi yang perlu diamati antara lain sebaran ukuran, kebiasaan makan, dan biologi reproduksi (Effendie, 1979), yang belum banyak diketahui.

Penelitian bertujuan untuk mempelajari aspek biologi ikan lidah (Achiroides leuchorhinchos) yang meliputi sebaran ukuran, bobot tubuh, kebiasaan makan, fekunditas, serta sebaran di Sungai Musi, Sumatera Selatan. 


\section{BAHAN DAN METODE}

Penelitian dilakukan pada tahun 2007 di Sungai Musi, Sumatera Selatan. Contoh didapatkan dari hasil eksperimen jaring selama 4 jam, jala 10 kali lempar, dan stroom, yang diperoleh dari 11 stasiun. Contoh kemudian dianalisis di Laboratorium Koleksi Ikan Balai Riset Perikanan Perairan Umum, Palembang.

Ikan contoh diidentifikasi dengan menggunakan buku Kottelat (1993); Weber \& de Beaufort (1929), lalu diukur panjang, ditimbang, dan dibedah untuk melihat isi saluran pencernaan dan gonad.

Pengukuran panjang total dengan menggunakan penggaris baja dengan ketelitian $1 \mathrm{~mm}$ dan bobot tubuh ditimbang dengan timbangan digital sartorius dengan ketelitian $0,01 \mathrm{~g}$.

Analisis hubungan panjang bobot dilakukan untuk melihat pola pertumbuhan ikan, berdasarkan pada Effendi (1979):

$\mathrm{W}=\mathrm{a} \mathrm{L}^{\mathrm{b}}$

di mana:

$\mathrm{W}=\operatorname{bobot}(\mathrm{g})$

$\mathrm{L} \quad=$ panjang $(\mathrm{cm})$

$\mathrm{a}, \mathrm{b}=$ konstanta

Pembagian kelas ukuran panjang dan bobot ikan dilakukan menurut Walpole (1992):

1. Penentuan banyak kelompok ukuran dengan rumus:

$N=1+3,32 \log N$

di mana:

$\mathrm{n}=$ jumlah kelas

$\mathrm{N}=$ jumlah ikan

2. Penentuan lebar kelas setiap kelas ukuran dengan rumus:

$C=\frac{a-b}{n}$

di mana:

$\mathrm{C}=$ lebar kelas

$\mathrm{a}=$ panjang atau bobot maksimum

$\mathrm{b}=$ panjang atau bobot minimum

$\mathrm{n}=$ jumlah kelas

Faktor kondisi ditentukan berdasarkan pada panjang dan bobot ikan. Ikan yang memiliki pola pertumbuhan allometrik, menggunakan rumus faktor kondisi sebagai berikut:

$$
K=\frac{W}{a L^{b}}
$$

di mana:

$$
\begin{array}{ll}
\mathrm{K} & =\text { faktor kondisi } \\
\mathrm{W} & =\text { bobot rata-rata ikan } \\
\mathrm{L} & =\text { panjang total rata-rata } \\
\mathrm{a} \text { dan } \mathrm{b} & =\text { konstanta dari regresi }
\end{array}
$$

Isi saluran pencernaan dianalisis dengan menggunakan indeks bagian terbesar (index of preponderance) menurut Effendie, 1992:

$$
I i=\frac{V i \times O i}{\sum(V i \times O i)} \times 100
$$

di mana:

$$
\begin{aligned}
& \mathrm{Ii}= \text { indeks bagian terbesar (index of } \\
& \text { preponderance) } \\
& \mathrm{Vi}=\text { persentase volume satu macam makanan } \\
& \mathrm{O} \mathrm{i}=\text { persentase frekuensi satu macam makanan }
\end{aligned}
$$

Jumlah dan ukuran telur dianalisis dengan cara membagi gonad menjadi 3 bagian, yaitu pangkal, tengah, dan ujung. Dari masing-masing bagian diambil contoh untuk dihitung dan diukur diameter.

\section{HASIL DAN BAHASAN}

\section{Morfologi}

Ikan lidah (Achiroides leuchorhinchos) (Gambar 1a) memiliki 49 sampai dengan 55 jari-jari sirip lemah sirip punggung dan 35 sampai dengan 38 jari-jari sirip lemah sirip dubur. Sirip punggung, sirip ekor, dan sirip dubur bersatu, tapi tidak memiliki sirip dada. Kedua mata sempurna dan terletak pada bagian badan yang berwarna coklat. Bagian bermata ikan ini mirip dengan Achiroides melanorhynchos, tetapi bagian badan yang tidak bermata pada A. Melanorhynchus memiliki tanda hitam di sekitar mulut, sedangkan $A$. leuchorhinchos tidak memiliki (Gambar 1b).

\section{Sebaran}

Ikan lidah (Achiroides leuchorhinchos) ditemukan di 11 stasiun yang tersebar dari hulu sampai dengan hilir Sungai Musi, yaitu Padang Tepong, Tabarena, Tanjung Raya, Begayut, Muara Abab, Pulokerto, Pulau Payung, Gandus, Mariana, SST, dan Muara Sungai Kramasan. Hal ini, sesuai dengan www.fishbase.com, bahwa ikan lidah (Achiroides leuchorhinchos) dapat hidup di air tawar, payau, dan laut. Ikan ini hidup di 
dasar perairan yang berlumpur atau di lumpur yang bercampur pasir dan di muara sungai.

\section{Distribusi Ukuran Panjang dan Bobot}

Distribusi panjang ikan yang diperoleh 34 sampai dengan $86 \mathrm{~mm}$ dengan rata-rata panjang $55,2 \mathrm{~mm}$ dan bobot tubuh 0,6 sampai dengan $10,6 \mathrm{~g}$ dengan rata-rata 3,5 g. Ikan lidah (Achiroides leuchorhinchos) terbanyak pada kisaran panjang 41 sampai dengan $48 \mathrm{~mm}$ (Gambar 2a) dan kisaran bobot 0,5 sampai dengan $1,9 \mathrm{~g}$ (Gambar $2 \mathrm{~b}$ ), sedangkan yang paling sedikit pada kisaran panjang 81 sampai dengan 88 $\mathrm{mm}$ dan pada kisaran bobot 6,5 sampai dengan 7,9 sama sekali tidak ditemukan.

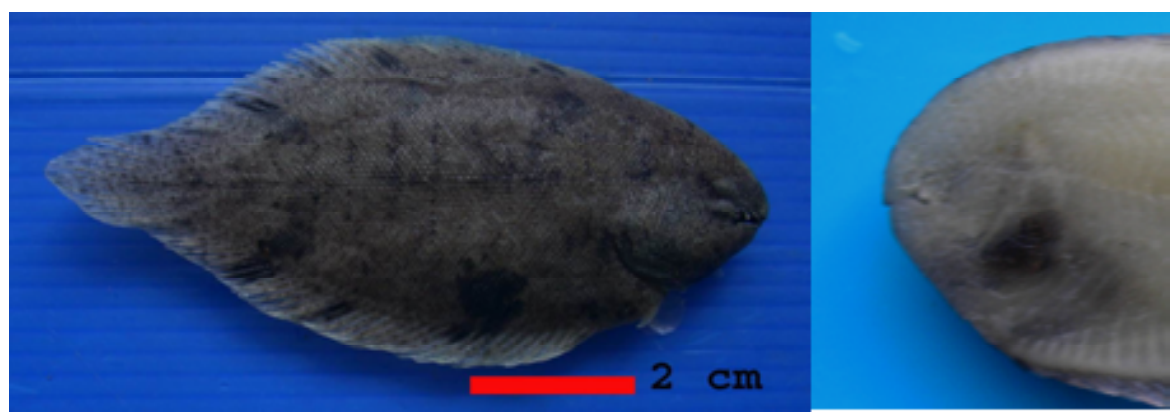

(a)

(b)

Gambar 1. Ikan lidah (Achiroides leuchorhinchos) a) bagian badan yang bermata da b) bagian badan yang tidak bermata.

Sumber foto: Tim F-IBI (2007)

Figure 1. Tongue fish (Achiroides leuchorhinchos) a) on eyes side and b) blind side.

Fhoto sources: Tim F-IBI (2007)
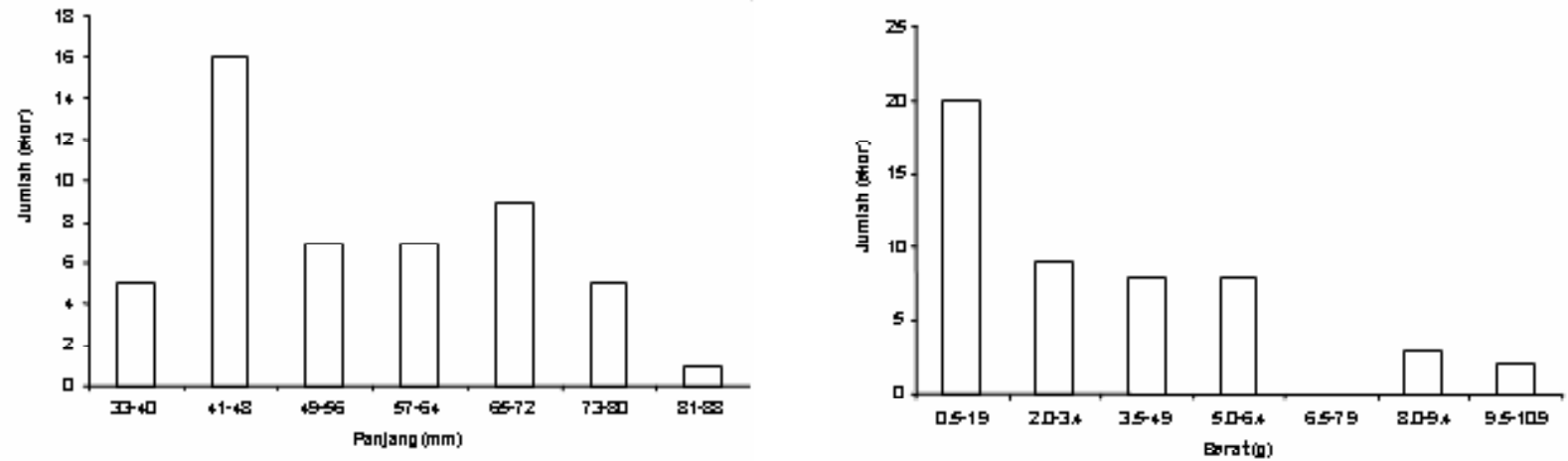

Gambar 2. $\quad$ a) kisaran panjang dan b) kisaran bobot ikan lidah (Achiroides leuchorhinchos).

Figure 2.

a) length frequency and b)weigth frequency tongue fish (Achiroides leuchorhinchos).

\section{Hubungan Panjang Bobot}

Berdasarkan pada hasil analisis hubungan panjang bobot, diperoleh nilai $b<3$, yaitu 2,894, hal tersebut menunjukkan bahwa ikan lidah (Achiroides leuchorhinchos) memiliki pola pertumbuhan allometrik negatif yang berarti pertumbuhan panjang lebih dominan daripada pertambahan bobot tubuh. Sedangkan nilai koefisien korelasi 0,988 menunjukkan bahwa antara panjang dan bobot tubuh memiliki hubungan yang erat (Gambar 3). Hal yang sama juga didapatkan oleh Rohmah (2007) pada ikan lidah (Cynoglossus lingua).

\section{Faktor Kondisi}

Faktor kondisi ikan lidah (Achiroides leuchorhinchos) bernilai 1,066. Menurut Lagler et al. (1977) nilai faktor kondisi antara 1 sampai dengan 3 dimiliki oleh ikan-ikan yang mempunyai bentuk badan pipih. Diduga faktor kondisi juga dipengaruhi oleh morfologi ikan.

\section{Komposisi Jenis Makanan}

Ikan lidah (Achiroides leuchorhinchos) memiliki panjang usus yang lebih pendek daripada panjang 
total tubuh. Nilai perbandingan antara panjang total dengan panjang usus 0,79 . Nilai perbandingan kurang dari 1 menunjukkan bahwa ikan lidah (Achiroides leuchorhinchos) merupakan ikan karnivor.

Jenis makanan yang didapatkan dari saluran pencernaan ikan lidah (Achiroides leuchorhinchos) adalah kepiting dan ikan. Dari nilai index of propenderence (Gambar 4) terlihat bahwa makanan utama ikan lidah (Achiroides leuchorhinchos) adalah kepiting (74\%) dan makanan pelengkap adalah ikan $(18 \%)$.

Selain itu, juga ditemukan lumpur atau pasir dalam jumlah yang cukup banyak (8\%). Diduga lumpur atau pasir ini terbawa pada saat ikan mengambil makanan di dasar.

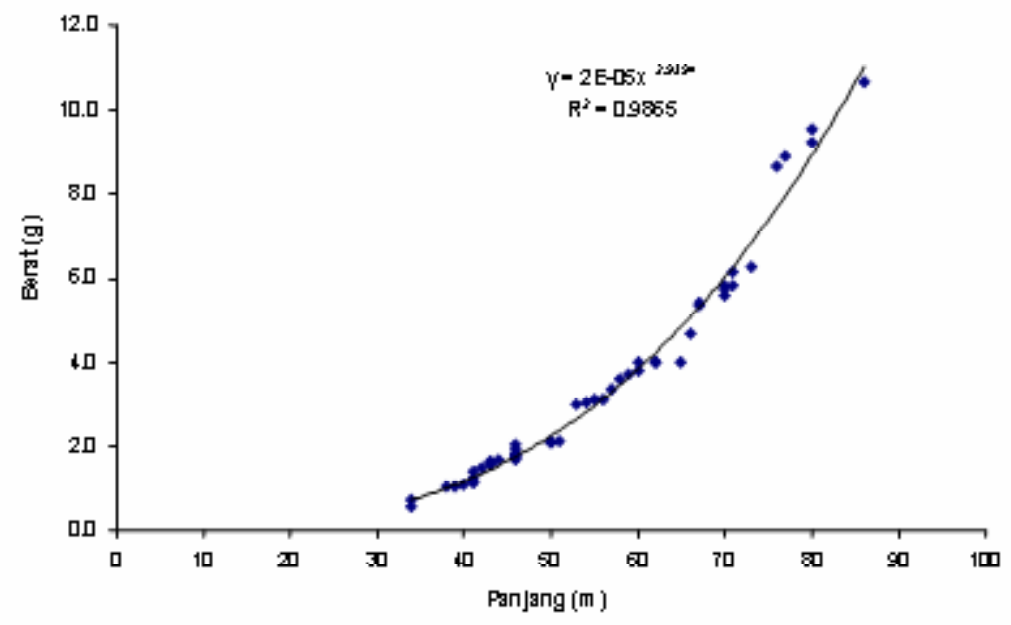

Gambar 3. Hubungan panjang bobot ikan lidah (Achiroides leuchorhinchos).

Figure 3. Length weight relationship of tongue fish (Achiroides leuchorhinchos).

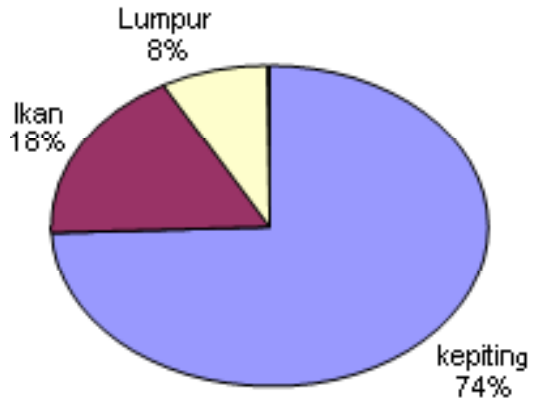

Gambar 4. Nilai indeks propenderesi ikan lidah (Achiroides leuchorhinchos).

Figure 4. Propenderence index value of tongue fish (Achiroides leuchorhinchos).

\section{Reproduksi}

Fekunditas adalah jumlah telur masak sebelum dikeluarkan pada waktu ikan memijah (Effendi, 1979). Fekunditas ikan lidah (Achiroides leuchorhinchos) diperoleh dari gonad IV yang didapatkan dari hasil penangkapan pada bulan Juli. Diduga musim pemijahan ikan lidah (Achiroides leuchorhinchos) terjadi pada bulan Juli yang termasuk musim kemarau. Pada saat ini, air sungai lebih dangkal sehingga intensitas cahaya yang sampai dengan ke dasar lebih banyak, suhu air lebih panas, dan kondisi perairan cenderung stabil. Kondisi demikian, merangsang ikan lidah (Achiroides leuchorhinchos) yang merupakan ikan demersal untuk memijah.

Ikan lidah (Achiroides leuchorhinchos) memiliki dengan jumlah telur rata-rata hampir $2 \times 103$ butir gonad dengan ukuran rata-rata 0,06 mm (Gambar 5).

Ukuran telur ikan lidah (Achiroides leuchorhinchos) cenderung seragam, diduga pola pemijahan ikan lidah (Achiroides leuchorhinchos) adalah total spawner. Artinya ikan lidah (Achiroides leuchorhinchos) mengeluarkan semua telur masak secara keseluruhan pada satu waktu pemijahan. 


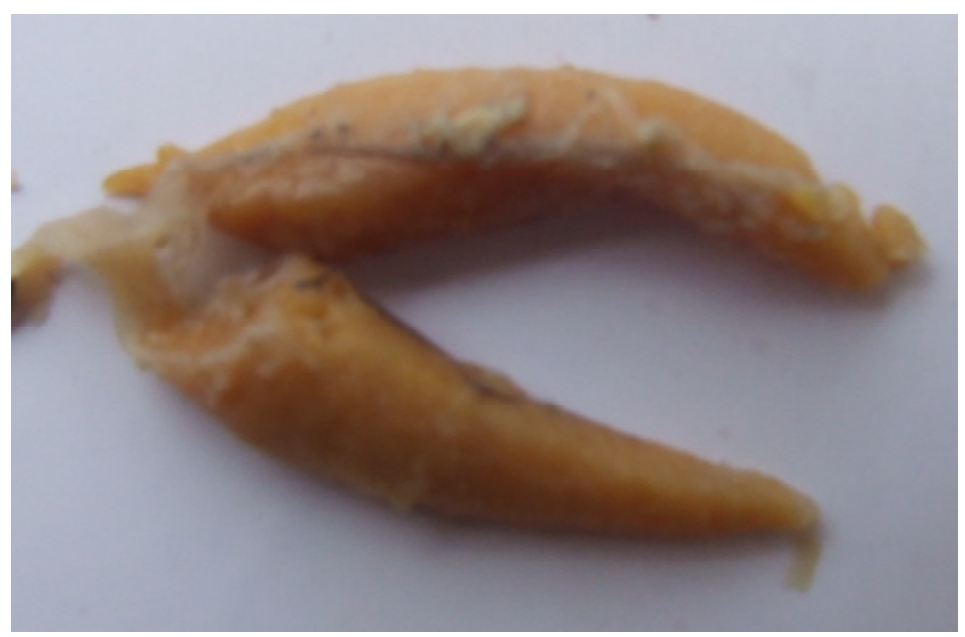

Gambar 5. Gonad ikan lidah (Achiroides leuchorhinchos).

Figure 5. Tongue fish's gonad(Achiroides leuchorhinchos).

\section{KESIMPULAN}

Ikan lidah (Achiroides leuchorhinchos) terdapat di Sungai Musi bagian hulu sampai dengan hilir. Analisis hubungan panjang bobot memperlihatkan ikan ini memiliki pola pertumbuhan allometrik negatif, di mana pertumbuhan panjang lebih cepat daripada pertumbuhan bobot dan terdapat hubungan yang erat antara panjang dengan bobot. Ikan terbanyak ditemukan pada kisaran panjang 41 sampai dengan $48 \mathrm{~mm}$ dan 0,5 sampai dengan $1 \mathrm{~g}$. Ikan lidah (Achiroides leuchorhinchos) merupakan ikan karnifora dengan kepiting sebagai makanan utama dan ikan sebagai makanan pelengkap. Pola pemijahan ikan lidah (Achiroides leuchorhinchos) diduga total spawner yang dicirikan dengan ukuran telur yang relatif seragam pada saat tingkat kematangan gonad IV, dengan fekunditas sekitar $2 \times 103$ butir telur dan ukuran rata-rata $0,06 \mathrm{~mm}$. Musim pemijahan ikan lidah (Achiroides leuchorhinchos) diduga terjadi pada bulan Juli yang merupakan musim kemarau.

\section{PERSANTUNAN}

Kegiatan dari hasil riset kajian tingkat degradasi lingkungan di perairan Sungai Musi, T. A. 2007, di Balai Riset Perikanan Perairan Umum-Mariana, Palembang. Penulis mengucapkan terima kasih yang sebesar-besarnya pada Dr. Husnah, M.Phil., Makri S.Pi., Herman, dan Budi Irawan atas dukungan dan bantuannya selama penelitian dan pembuatan tulisan ini.

\section{DAFTAR PUSTAKA}

Effendie, M. I. 1979. Biologi perikanan. Yayasan Pustaka Nusatama. Yogyakarta.

Effendie, M. I. 1992. Metode biologi perikanan. Yayasan Agromedia. Bogor.

http://www.fishbase.com/Summary/species Summary.php? ID =25162\&genusname $=$ Achiroides\&speciesname=leucorhynchos. Rabu 9 April 2008. Jam 14.30 WIB.

Kottelat, M., A. J. Whitten, S. N. Kartikasari, \& S. Wirjoatmojo.1993. Freshwater fishes of western Indonesia and Sulawesi (Ikan air tawar Indonesia bagian barat dan Sulawesi). Periplus EditionsEMDI Project. Jakarta.

Rohmah, S. 2007. Kebiasaan makanan ikan lidah (Cynoglossus lingua) periode bulan Pebruari sampai dengan Juli 2006 di perairan Ujung Pangkah, Gresik, Jawa Timur. Departemen Manajemen Sumber Daya Perairan. Fakultas Perikanan dan IImu Kelautan. Insitut Pertanian Bogor. Bogor.

Walpole, R. E. 1992. Pengantar statistika (Diterjemahkan oleh Bambang Sumantri). Edisi Ke3. PT Gramedia. Jakarta.

Weber, M. \& L. F. De Beaufort. 1929. The fishes of Indo-Australian Archipelago. V. Anacanthini, Allotriognathi, Heterosomata, Berycomorphi, and Percomorphi. Brill. Leiden. 